\title{
Ectopic Prolactin Secretion Syndrome
}

National Cancer Institute

\section{Source}

National Cancer Institute. Ectopic Prolactin Secretion Syndrome. NCI Thesaurus. Code C8441.

A syndrome characterized by abnormal secretion of prolactin in conjunction with neoplastic growth occurring anywhere in the body. 